\title{
Do lumen-apposing metal stents (LAMS) improve treatment outcomes of walled-off pancreatic necrosis over plastic stents using dual-modality drainage?
}

\section{(c) $(1)$}

\author{
Authors \\ Nadav Sahar, Richard Kozarek, Zaheer S. Kanji, Andrew S. Ross, Michael Gluck, S. Ian Gan, Michael Larsen, \\ Shayan Irani
}

Institution

Division of Gastroenterology and Hepatology, Virginia Mason Medical Center, Seattle, Washington, United States

submitted 21.12.2016

accepted after revision: 15.5 .2017

\author{
Bibliography \\ DOI https://doi.org/10.1055/s-0043-111794 | \\ Endoscopy International Open 2017; 05: E1052-E1059 \\ (c) Georg Thieme Verlag KG Stuttgart · New York \\ ISSN 2364-3722
}

Corresponding author

Shayan Irani, Division of Gastroenterology and Hepatology, Virginia Mason Medical Center, 1100 Ninth Avenue,

C3-GAS, Seattle, WA 98101

Fax: +1-206-625-7195

Shayan.Irani@virginiamason.org

\section{ABSTRACT}

Background and study aims Endoscopic ultrasoundguided drainage of symptomatic walled-off pancreatic necrosis (WON) usually has been performed with double pigtail plastic stents (DPS) and more recently, with lumen-ap- posing metal stents (LAMS). However, LAMS are significantly more expensive and there are no comparative studies with DPS. Accordingly, we compared our experience with combined endoscopic and percutaneous drainage (dualmodality drainage [DMD]) for symptomatic WON using LAMS versus DPS.

Patients and methods Patients who underwent DMD of WON between July 2011 and June 2016 using LAMS were compared with a matched group treated with DPS. Technical success, clinical success, need for reintervention and adverse events $(\mathrm{AE})$ were recorded.

Results A total of 50 patients ( 31 males, 25 patients treated with LAMS and 25 patients treated with DPS) were matched for age, sex, computed tomography severity index, and disconnected pancreatic ducts. Technical success was achieved in all patients. Mean days hospitalized post-intervention (14.5 vs. $13.1, P=0.72$ ), time to resolution of WON ( 77 days vs. 63 days, $P=0.57$ ) and mean follow-up (207 days vs. 258 days, $P=0.34$ ) were comparable in both groups. AEs were similar in both groups ( 6 vs. $8, P=0.53$ ). Patients treated with LAMS had significantly more reinterventions per patient ( 1.5 vs. $0.72, P=0.01)$.

Conclusions In treatment of symptomatic WON using DMD, LAMS did not shorten time to percutaneous drain removal and was not associated with fewer AEs.

\section{Introduction}

Walled-off pancreatic necrosis (WON) can be seen in up to $20 \%$ of cases of severe acute pancreatitis (SAP). It evolves approximately 4 weeks after the initial diagnosis of SAP and is usually detected by contrast-enhanced computed tomography (CT) scan [1,2]. Drainage of WON should be reserved for infection, gastric outlet obstruction, biliary obstruction or intractable pain.

Historically, surgical debridement was the treatment of choice for symptomatic WON [3]. However, over the last decade, less invasive endoscopic and percutaneous approaches have emerged with reduced morbidity and mortality [4-6]. Endoscopic ultrasound-guided drainage of WON with or with- out necrosectomy maintaining access to the necrosum, a minimally invasive treatment option, has been conventionally performed with double pigtail plastic stents (DPS). Disadvantages of DPS alone without necrosectomy have been the high rates of infection due to stent occlusion, which can be seen in $18 \%$ to $40 \%$ of patients $[7,8]$. Fully covered self-expanding metal stents (biliary and esophageal) with a larger diameter have allowed better, more rapid drainage and are less likely to occlude, but are more prone to migration $[9,10]$. More recently, lumenapposing metal stents (LAMS) (AXIOS; Boston Scientific, Natik, $M A)$, have been increasingly used because of the advantage of better lumen apposition and wider diameter, improving access for endoscopic debridement. Reports have suggested their use to be safe and effective for draining WON [11-13], although 
more recently some adverse events (AEs) such as bleeding have been reported [14]. LAMS are substantially more expensive and there are no comparative studies with DPS $[15,16]$.

Over the past decade, our tertiary care referral center for pancreatitis has adopted a combined method of endoscopic and percutaneous drainage called dual modality drainage (DMD) for symptomatic WON [17-19]. The percutaneous drains allow irrigation and drainage of the necrosis while the transgastric stents aid with egress of some necrosis and treat an eventual disconnected gland which can be seen in up to 50 $\%$ of patients in some series [19]. By doing so, we have eliminated pancreaticocutaneous fistulas that were previously observed in $20 \%$ of cases drained solely by the percutaneous route [20]. With this technique, we have noted disease-related mortality as low as $3.4 \%$ and no intraprocedural mortality. We have not needed to perform necrosectomy (endoscopic or surgical) in any patient, thereby eliminating adverse events as high as $26 \%$ in some series $[21,22]$.

We sought to retrospectively analyze and compare the outcomes of DMD of WON using LAMS and DPS within our tertiary care pancreatic center. We hypothesized that use of DPS may show equal clinical efficacy when compared to LAMS for DMD of WON and be associated with fewer interventions.

\section{Patients and methods}

Patients who had undergone DMD of WON at our institution between July 2011 and June 2016 were included in the study. The study was approved by the institutional review board at our institution. The diagnosis of WON was made either by CT or magnetic resonance imaging (MRI) according to the Revised Atlanta Classification [23]. A retrospective review of CT scans was made before 2013 to ensure that all scans were accurately compared. All cases of WON were diagnosed on imaging by a hospital radiologist and were also evaluated by a gastroenterologist. In cases of disagreement between reads, a second radiologist was asked for a new read.

Patients were managed by DMD if they demonstrated evidence of: (1) infected WON; (2) gastric outlet obstruction; (3) biliary obstruction; or (4) intractable abdominal pain. Patients were graded according to severity of disease as defined by the CT severity index (CTSI) [24], American Society of Anesthesiologists (ASA) grading score and size of the WON defined radiologically. Other measurements of pancreatitis severity, such as the Ranson criteria or the Acute Physiology, Age and Chronic Evaluation II (APACHE II), were not reported as the majority of patients were referred from outside hospitals, precluding accurate baseline measurement.

\section{Dual-modality drainage technique}

DMD was performed as per our institution's specific protocol [18]. All patients received pre-procedure antibiotics, usually a quinolone if they weren't already on antibiotics for infected necrosis. CT-guided, 8-10 F percutaneous drain/s were inserted into the WON by an interventional radiologist. Patients were then transferred to the endoscopy suite, where EUS-guided transgastric stents (without necrosectomy) were usually placed under general anesthesia. Procedures were performed by one of 5 endoscopists with a therapeutic linear array echoendoscope (Olympus Medical Systems; Center Valley, PA). The necrotic cavity was punctured with a 19-gauge needle through which a 0.025-inch (Visiglide, Olympus Medical Systems; Center Valley, PA) or 0.035-inch guidewire (Jagwire, Boston Scientific, Natik, MA) was advanced into the cavity. Balloon dilation with a CRE balloon $(8-10 \mathrm{~mm}$ or $10-12 \mathrm{~mm})$ in some cases preceded by a 4 to $7 \mathrm{Fr}$ dilating catheter (Cook) was performed, followed by placement of $27 \mathrm{Fr} \times 3-\mathrm{cm}$ DPS. In case of LAMS [all cases were done with non-cautery enhanced LAMS, (AXIOS; Boston Scientific, Natik, MA)], a 4-mm balloon dilation was performed to allow advancement of the prosthesis into the necrosis. A $7 \mathrm{Fr} \times 3-\mathrm{cm}$ DPS in addition was placed through the lumen of the LAMS to reduce risk of injury to the contralateral necrotic cavity wall and internal migration of the LAMS [25]. The selection of a $10-\mathrm{mm}$ or $15-\mathrm{mm}$ diameter LAMS was at the discretion of the endoscopist. Concurrent endoscopic retrograde cholangiopancreatography (ERCP) was performed at the discretion of the endoscopist to identify and potentially treat pancreatic duct leak/blowout to identify a disconnected pancreatic duct. Those who did not undergo ERCP to assess for a disconnected pancreatic duct were evaluated with magnetic resonance cholangiopancreatography once the collection had resolved.

Patients were followed in clinic after discharge from the hospital. CT scans and percutaneous tube assessments were ordered routinely at 14- to 21-day intervals as part of follow-up to assess for need to upsize, reposition or remove the percutaneous drains. Percutaneous drain occlusions and dislodgements were managed with CT scans and tube checks. The transgastric stents were left in situ indefinitely if there was evidence of a disconnected pancreatic duct, either at ERCP or at the end of treatment using MRCP.

\section{Cost analysis}

Costs of stents and other medical equipment related to the endoscopic drainage were calculated.

\section{Definitions}

Technical success was defined as the ability to place the percutaneous drain and the transgastric stents into the WON as confirmed radiographically and by flow of necrotic material. Clinical success was defined as ability to remove the percutaneous drain once the necrotic cavity had resolved as confirmed by CT scan without recurrence of fluid collection over the ensuing 4 weeks. Disconnected pancreatic duct syndrome (DPDS) was defined at ERCP with complete blowout or complete cut off of PD with inability to demonstrate the tail of the pancreas (which was still visible on CT imaging) or on MRCP after resolution of WON demonstrating loss of pancreatic duct between the head and the tail of the pancreas. A reintervention was defined as any procedure performed after the index procedure for drainage. These were further divided into procedures to address the transgastric stents, and other procedures which included ERCP for biliary reasons, placement/replacement of enteric feeding tubes, and tube checks to reposition/replace/add/upsize percutaneous drains as deemed appropriate. Adverse events (AEs) 
- Table 1 Characteristics of patients undergoing dual-modality drainage (DMD) of symptomatic walled off necrosis (WON) comparing lumenapposing metal stents (LAMS) $n=25$ to double pigtail plastic stents (DPS) $n=25$.

\begin{tabular}{|c|c|c|c|}
\hline & LAMS $(n=25)$ & DPS $(n=25)$ & $P$ value \\
\hline Mean age (range) & $51.2(28-73)$ & $53.2(20-81)$ & 0.65 \\
\hline Male (\%) & $17(68)$ & $14(56)$ & 0.76 \\
\hline \multicolumn{4}{|l|}{ Etiology of pancreatitis (\%) } \\
\hline - Gallstone & $13(52)$ & $12(48)$ & \\
\hline - Alcohol & $4(16)$ & $5(20)$ & \\
\hline - Idiopathic & $7(28)$ & $5(20)$ & \\
\hline - Hypertriglyceridemia & $0(0)$ & $3(12)$ & \\
\hline - Pancreas divisum & $1(4)$ & $0(0)$ & \\
\hline \multicolumn{4}{|l|}{ Indication for drainage (\%) } \\
\hline - Intractable pain and weight loss & $12(48)$ & $12(48)$ & \\
\hline - Gastric outlet obstruction & $6(24)$ & $7(28)$ & \\
\hline - Infection & $6(24)$ & $4(16)$ & \\
\hline - Biliary obstruction & $1(4)$ & $2(8)$ & \\
\hline Mean BMI (range) & $30.2(19-42.6)$ & $30.5(18.3-47.7)$ & 0.86 \\
\hline Mean CTSI score (range) & $8.5(5-10)$ & $7.9(4-10)$ & 0.21 \\
\hline Mean ASA score (range) & $2.5(2-4)$ & $2.6(2-4)$ & 0.64 \\
\hline Mean lowest albumin g/dL (range) & $2.5(1.7-3.7)$ & $2.38(1.7-3.3)$ & 0.39 \\
\hline Mean CRP mg/L (range) & $126(6-406)$ & $149(3-348)$ & 0.55 \\
\hline $\begin{array}{l}\text { Mean number of days from onset of severe acute pancreatitis } \\
\text { (SAP) to DMD (range) }\end{array}$ & $116(26-685)$, median 60 & $72(21-360)$, median 37 & 0.14 \\
\hline Mean WON size in cm (range) & $15.3(9.3-23.2)$ & $13.7(7.5-24.4)$ & 0.14 \\
\hline Disconnected pancreatic ducts (\%) & $16(64)$ & $15(60)$ & 0.77 \\
\hline
\end{tabular}

were defined as procedure or stent-related events occurring within 30 days of the procedure according to the ASGE Lexicon [26].

\section{Outcomes}

The primary outcome of this study was clinical success. Secondary outcomes were the need for re-intervention and the rates of AEs in LAMS or DPS. Patients were followed up for 6 months from percutaneous drain removal.

\section{Statistical analysis}

Comparative analysis between the 2 groups was performed using the 2-tailed Student's $t$ test for continuous variables and the $\mathrm{chi}^{2}$ test for categorical variables. $P$ values $\leq 0.05$ were considered significant. Analyses were done using Stata 14.0 (StataCorp, College Station, TX).

\section{Results}

Twenty-five consecutive patients with WON treated with LAMS were matched using propensity score analysis with 25 equivalent patients treated with DPS using DMD. The most common etiology for pancreatitis was choledocholithiasis (52\% for LAMS vs. $48 \%$ for DPS), followed by idiopathic ( $28 \%$ vs. $20 \%$ ) and alcohol (16\% vs. $20 \%)$. Baseline characteristics of patients were carefully matched for demographics, clinical, laboratory and imaging parameters between the LAMS and DPS groups. Patients were predominantly male in each group $(68 \%$ vs. $56 \%, P=0.76)$ with a mean age of 51 and 53 years, $(P=0.65)$ for the LAMS and DPS groups, respectively. Mean body mass index (BMI) scores (30.2 vs. 30.5, $P=0.86$ ), lowest mean albumin recorded during hospitalization $(2.5 \mathrm{~g} / \mathrm{dL}$ vs $2.38 \mathrm{~g} / \mathrm{dL}, \mathrm{p}=$ $0.39)$ and mean C-reactive protein (CRP) levels $(126 \mathrm{mg} / \mathrm{L}$ vs. $149 \mathrm{mg} / \mathrm{L}, P=0.55$ ) were similar. Computed tomography severity index (CTSI) 8.5 vs. $7.9(P=0.21)$ and American Society of Anesthesiologists (ASA) scores 2.5 vs. $2.6(p=0.64)$ were also carefully matched. ( $\triangleright$ Table 1 ). Indications for drainage were 
- Table 2 Clinical outcomes and procedure characteristics of patients undergoing dual-modality drainage (DMD) of symptomatic walled off necrosis (WON) comparing self-expanding lumen-apposing metal stents (LAMS) $n=25$ vs. double pigtail plastic stents (DPS) $n=25$.

\begin{tabular}{|c|c|c|c|}
\hline & LAMS $(n=25)$ & DPS $(n=25)$ & $P$ value \\
\hline Mean duration of hospitalization in days after DMD (range) & $14.5(1-58)$ & $13.1(1-46)$ & 0.72 \\
\hline Technical success (\%) & $25(100)$ & $25(100)$ & \\
\hline Mean number of ERCP/patient (range) & $0.88(0-5)$ & $0.72(0-3)$ & 0.57 \\
\hline Mean number of percutaneous drains/patient (range) & $1.2(1-3)$ & $1.3(1-3)$ & 0.35 \\
\hline Mean number of days to resolution of WON (range) & $77.6(8-186)$, median 78 & $63.4(16-142)$, median 59 & 0.21 \\
\hline Mean number of CTs after DMD (range) & $6.2(1-19)$ & $5.7(1-12)$ & 0.69 \\
\hline Mean number of percutaneous tube checks after DMD (range) & $6.3(1-20)$ & $4.8(1-11)$ & 0.19 \\
\hline Mean number of stent related re-interventions/patient (range) & $0.9(0-1)$ & $0.08(0-1)$ & $0.01^{*}$ \\
\hline $\begin{array}{l}\text { Mean number of re-interventions not related to transgastric stent/ } \\
\text { patient (range) }\end{array}$ & $0.36(0-2)$ & $0.48(0-4)$ & 0.63 \\
\hline Mean follow- up in days (range) & $207(41-512)$ & $258(42-621)$ & 0.34 \\
\hline
\end{tabular}
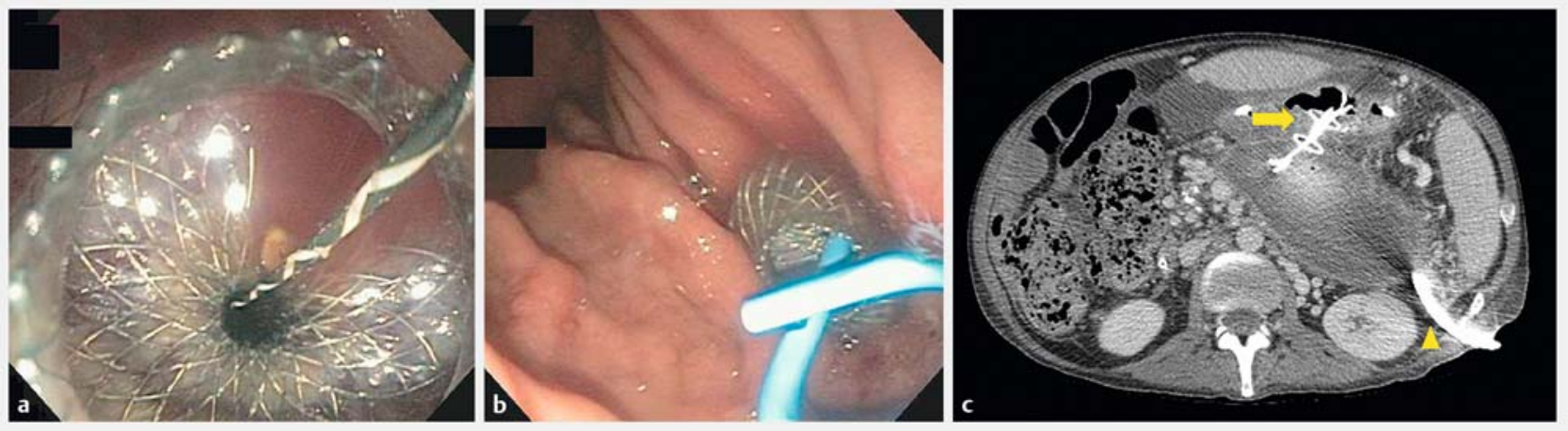

- Fig. 1 a Endoscopic view of a lumen-apposing metal stent (LAMS) deployed into the walled-off pancreatic necrosis (WON). b Placement of a $7-\mathrm{Fr} \times 3-\mathrm{cm}$ double pigtail stent (DPS) placed through it. c Computed tomography scan 3 weeks later demonstrates air in the WON (yellow arrow) with transgastric LAMS, pigtail stent and percutaneous drain (yellow arrowhead) in appropriate place.

also comparable in both groups; intractable pain with weight loss ( $48 \%$ vs. $48 \%)$, gastric outlet obstruction ( $24 \%$ vs. $28 \%$ ) and ongoing infection ( $24 \%$ vs. $16 \%)$. The mean time of intervention/drainage from the onset of pancreatitis was longer for LAMS but not statistically significant ( 116 days vs. 72 days, $P=$ 0.24, ). Rates of disconnected pancreatic duct were high and similar in both groups in $64 \%$ of the LAMS group compared to $60 \%$ in the DPS group $(P=0.77)$.

Technical success was achieved in $100 \%$ of cases in both groups ( $\vee$ Table 2 ). Drainage in all 50 patients was via a transgastric approach ( $\triangleright$ Fig. $\mathbf{1}$, $>$ Fig. 2 ). In the LAMS group, the 10 -mm stent was chosen in 14 patients (56\%) and the $15-\mathrm{mm}$ stent in 11 patients (44\%). In the DPS group, an 8- to $10-\mathrm{mm}$ CRE balloon was used in 15 patients and a 10- to 12 -mm CRE balloon was used in 10 patients. Seventeen patients in the LAMS group (68\%) underwent a mean of $0.88 \mathrm{ERCP} /$ patient and 11 patients in the DPS group (44\%) underwent a mean of
0.72 ERCPs/patient $(P=0.57)$ to assess for an ongoing pancreatic duct leak or presence of a disconnected pancreatic duct syndrome. The remaining patients underwent an MRCP after resolution of the necrotic collection, to assess for a disconnected pancreatic duct syndrome.

At study completion, 3 of 25 patients in the LAMS group still had a percutaneous drain, awaiting resolution of WON with clinical success in the remainder. Complete resolution of WON was seen in 24 out of the 25 patients in the DPS group. One patient in the DPS group died at 41 days after initial drainage. He had 3 admissions for melena, with no definitive source of bleeding found. The suspicion was for bleeding from the gastric puncture site or the necrotic cavity and despite multiple endoscopies and embolization of a suspected branch of the splenic artery, when he represented with a third episode of bleeding, the family decided to withdraw care, given his age and other comorbidities. 

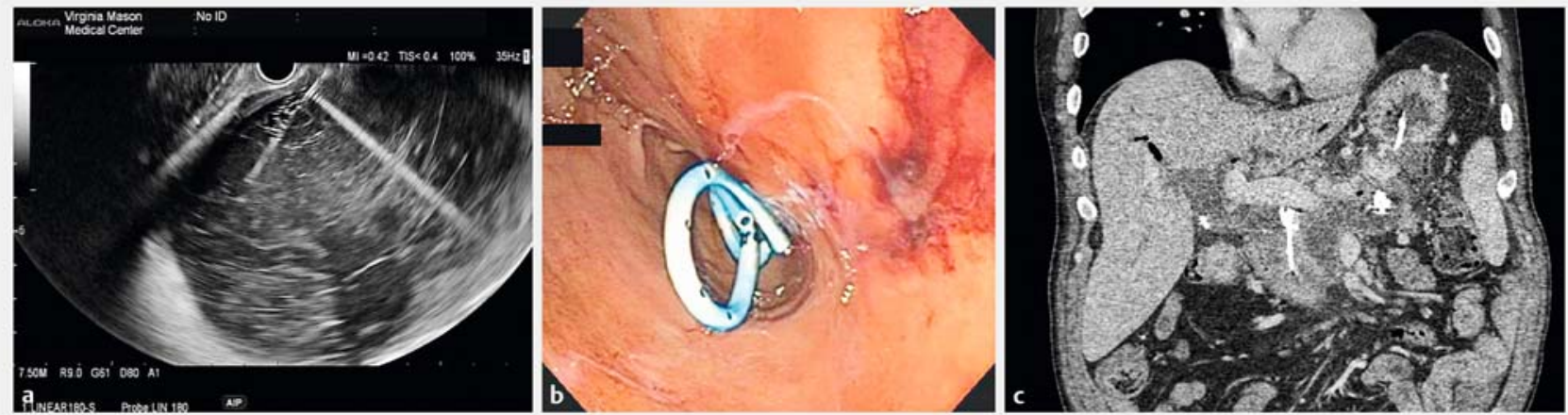

- Fig. 2 a A 7.5-MHz endoscopic ultrasound image of WON punctured with a 19-gauge needle to create a cystgastrostomy. b Endoscopic image of $27 \mathrm{Fr} \times 3-\mathrm{cm}$ double pigtail stents placed into the WON through the cystgastrostomy. c Computed tomography image of a transgastric double pigtail stent and percutaneous drain within the WON.

There was no difference in mean time from initiation of drainage to resolution of WON and removal of percutaneous drain (time to clinical resolution) between LAMS and DPS groups ( 77 days vs. 63 days, $P=0.21$ ). Mean follow-up was comparable in the 2 groups and was 207 days for the LAMS group and 258 days for the DPS group $(P=0.34)$.

There was a significant difference in reinterventions to address the transgastric stents in the 2 groups. 23 patients in the LAMS group underwent endoscopy to remove $(n=7)$ or replace $(n=16)$ the LAMS with 2 DPS (as in cases of disconnected pancreatic duct syndrome) compared to 2 patients in the DPS group where the stents were removed at the end of treatment (no disconnected pancreatic duct). The mean number of stentrelated reinterventions/patient was 0.92 compared to 0.08 respectively, $(P=0.01)$. Other reinterventions (not related to transgastric stents) were similar in the 2 groups (0.36 mean interventions per patient in LAMS group vs. 0.48 in DPS group, $P=0.48)$.

Radiology utilization was also similar in both groups. No difference was noted for the total number of CT scans performed after initial drainage until complete resolution (6.2 for LAMS vs. 5.7 for DPS, $P=0.69)$. Likewise, there were a similar number of percutaneous tube checks in both groups (6.3 vs. $4.8, P=0.19$ ), most commonly due to percutaneous drain occlusion necessitating replacement ( $62 \%$ vs. $60 \%$ ) or just routine checks $(29 \%$ vs. $36 \%$ ). No patient in either group required surgical intervention.

AEs were similar in both groups (6 LAMS patients vs. 8 DPS patients, $P=0.53)$. In the LAMS group, 1 patient developed significant bleeding upon needle puncture, which was thought to be adequately controlled with tamponade by the LAMS. However, he rebled 3 days later. This was successfully treated with endoscopic cyanoacrylate injection of a perigastric varix under the LAMS. Another patient developed a large colonic fistula from erosion of the distal flange into the splenic flexure. This was first noted on a routine tube check 73 days after initial drainage. Despite removal of the LAMS, the fistula persisted for 3 months, until eventual successful closure with an overthe-scope clip via colonoscopy ( $\triangleright$ Fig.3). Four more patients were readmitted for fever and presumed infection related to the drain and were accordingly treated with antibiotics and tube changes.

Eight complications were noted in the DPS group (28\%). Bleeding was seen in 3 patients. One patient was treated successfully with endoscopic cyanoacrylate injection of a 3-mm left gastroepiploic artery pseudoaneurysm (13 days after initial drainage). A second patient required angiographic embolization of the left gastric artery (4 hours after initial drainage). In the third patient, who had 2 prior episodes of bleeding without a source found, the patient's family decided to withdraw care, resulting in his death 6 weeks after initial drainage. Five patients were readmitted for recurrent infection and treated with IV antibiotics and tube change.

Internal migration of the stent was seen in 1 patient in each group during the index drainage procedure. In both cases, the stent was pulled back and repositioned without the need for an additional stent. This was not an AE.

Cost comparison between the 2 groups were also performed ( $\triangleright$ Table 3 ). For the LAMS group, the cost of the noncautery-enhanced LAMS in addition to an extra plastic stent, the access needle required, the guidewire and the CRE balloon was $\$ 4,798$ USD per patient. For the DPS group, cost per patient totaled \$817USD per patient.

\section{Discussion}

Management of symptomatic WON has evolved significantly from a surgical approach to minimally invasive, step-up approach over the last decade [6]. Endoscopic drainage techniques have become the standard of care at experienced tertiary care centers $[8,27,28]$. Dual-modality drainage for symptomatic WON combining transgastric and percutaneous drainage has been successfully performed with demonstrated efficacy and safety at our institution with no need for surgical interventions, no intraprocedural mortaility, and no pancreaticocutaneous fistulas despite a rate of $64 \%$ disconnected pancreatic ducts [19]. With the increasing use of LAMS and their cited benefits for endoscopic drainage of WON, we wanted to see if this 

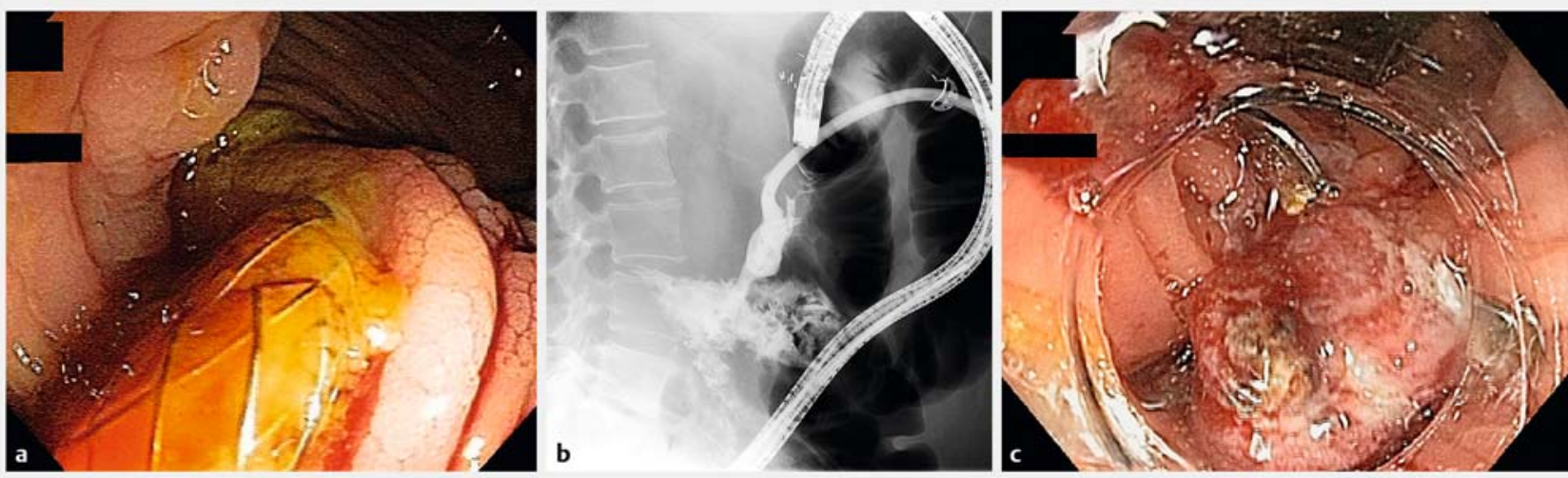

- Fig. 3 a Endoscopic view of the splenic flexure demonstrating migration of lumen-apposing metal stent (LAMS) into the colon (colonic fistula). b Fluoroscopic view of a persistent fistula 3 months later. c Deployment of a 12/6a over the scope clip to successfully close the fistula.

- Table 3 Endoscopic costs per patient for dual modality drainage (DMD) of walled off necrosis (WON) comparing self-expanding lumen-apposing metal stents (LAMS) to double pigtail plastic stents (DPS).

\begin{tabular}{|l|c|c|}
\hline & LAMS (Price in US Dollars) & DPS (Price in US Dollars) \\
\hline Non-cautery-enhanced LAMS & $\$ 4100$ & $\$ 250$ \\
\hline 19 -gauge access needle & $\$ 250$ & $\$ 142$ \\
\hline Jagwire & $\$ 142$ & $\$ 250$ \\
\hline Dilating balloon & $\$ 250$ & $\$ 63$ \\
\hline $\begin{array}{l}\text { Dilating catheter 4-7 FR } \\
7 \times 3 \text { Fr plastic pigtail biliary stent }\end{array}$ & - & $\$ 112$ \\
\hline Total & $\$ 56$ & $\$ 817$ \\
\hline
\end{tabular}

new prosthesis hastened recovery in patients managed using our technique of DMD.

The design of this stent as a saddle-like device is intended to limit migration. Its large diameter $(10 \mathrm{~mm}$ or $15 \mathrm{~mm})$ faciliates better drainage and easy passage of the endoscope to perform necrosectomy. A recent multicenter retrospective study comparing these 2 stents for drainage of WON has shown LAMS to be superior in terms of clinical success as measured by remission of WON, number of interventions required and rates of adverse events [16]. However, patients drained with LAMS underwent considerably higher rates of direct necrosectomy compared to DPS ( $44 \%$ vs. $1.7 \%, P<0.01)$, a more likely explanation of the above results rather than the stent type.

Our study failed to show any advantage of using LAMS over DPS for drainage of WON using DMD. Our primary end point measuring clinical success with a 6-month follow-up was similar in both groups, with a mean number of days to drain removal of 77 with LAMS vs. 63 with DPS with no statistically significant difference. This is consistent with data from previous larger series [19]. The total number of reinterventions in the LAMS group in our study was significantly higher. This is accounted for by the fact that every LAMS has to be removed once placed. Not only has the stent dwell time been approved for 60 days by the US Food and Drug Administration, leaving a metal stent in long term, especially in case of a disconnected pancreatic duct, potentially increases the risk of bleeding, injury to structures in the lesser sac, and may be a less effective drainage strategy for the disconnected tail compared to 2 DPS, which allow "wicking" of pancreatic juice between them. DPS, on the other hand, are left in place indefinitely in case of a disconnected pancreatic duct syndrome which was seen in $60 \%$ of these patients. In patients who had LAMS and a disconnected pancreatic duct syndrome (67\% of cases), LAMS was replaced with 2 DPS to provide long-term drainage of the orphan pancreatic tail, a method that has long term evidence of its efficacy in reducing recurrent pancreatic fluid collections $[29,30]$. When comparing the number of re-interventions not related to removal of the stent itself, there were no significant differences.

No differences were detected in the rates of AEs between the 2 groups. The most common AE with both stents was an infection related to the drained WON which in all cases was managed with antibiotics and/or tube checks or changes. There was no need for surgical intervention in either group and more importantly no mortality was attributed to the index procedure itself. The only death (4\%) seen in the DPS group was unrelated to the procedure. This concurs with our experience previously reported in a larger series, where the mortality was $3.4 \%$ in a study of 103 patients [19]. 
The equipment cost using LAMS are significantly higher than that for using DPS per patient ( $\$ 4,798$ USD vs. \$819USD). The combination of cost and the resulting fewer interventions using DPS argues against routine use of LAMS for DMD of WON.

Limitations of this study include the retrospective design, small sample size, and relatively short follow-up. A power calculation was not performed as this was a retrospective review of our single-center experience where we included all available patients in the prescribed timeframe. We realize the study could be underpowered to detect a difference. Such a limitation could be avoided with larger retrospective studies or a prospective study. In addition, being from a single tertiary center where the treatment of WON is by DMD, extrapolation to other centers with different techniques of treating WON and varying experience, cannot be made at this time. Although the sample size was small, the groups were well-matched.

\section{Conclusion}

In conclusion in treatment of WON using DMD, LAMS did not shorten time to percutaneous drain removal and was not associated with fewer AEs. In addition, LAMS were associated with increased upfront costs and overall costs given the need for significantly more interventions, compared to DPS. A prospective study comparing LAMS to DPS using different techniques of treating WON would be helpful.

\section{Competing interests}

Dr. Irani is a consultant for Boston Scientific with remittance to the clinic. Dr. Ross is a consultant for Boston Scientific with remittance to the clinic. Dr. Kozarek received paid research support for the medical center for 3 clinical trials supported by Boston Scientific which acquired Axios stent. None of the trials dealt with the Axios stent or the data presented in this manuscript.

\section{References}

[1] Forsmark CE, Baillie J et al. Practice AGAIC. AGA Institute technica review on acute pancreatitis. Gastroenterology 2007; 132: 2022 2044

[2] Baron TH, Morgan DE. Acute necrotizing pancreatitis. N Engl J Med 1999; 340: $1412-1417$

[3] Bradley EL3rd, Howard T], van Sonnenberg E et al. Intervention in necrotizing pancreatitis: an evidence-based review of surgical and percutaneous alternatives. J Gastrointest Surg 2008; 12: 634-639

[4] Bakker OJ, van Santvoort HC, van Brunschot S et al. Endoscopic transgastric vs surgical necrosectomy for infected necrotizing pancreatitis: a randomized trial. JAMA 2012; 307: 1053-1061

[5] Freeman ML, Werner J, van Santvoort HC et al. Interventions for necrotizing pancreatitis: summary of a multidisciplinary consensus conference. Pancreas 2012; 41: 1176-1194

[6] van Santvoort HC, Besselink MG, Bakker O] et al. A step-up approach or open necrosectomy for necrotizing pancreatitis. N Engl J Med 2010; 362: $1491-1502$
[7] Singhal S, Rotman SR, Gaidhane M et al. Pancreatic fluid collection drainage by endoscopic ultrasound: an update. Clin Endosc 2013; 46: $506-514$

[8] Varadarajulu S, Bang JY, Phadnis MA et al. Endoscopic transmural drainage of peripancreatic fluid collections: outcomes and predictors of treatment success in 211 consecutive patients. J Gastrointest Surg 2011; 15: 2080-2088

[9] Chandran S, Efthymiou M, Kaffes A et al. Management of pancreatic collections with a novel endoscopically placed fully covered self-expandable metal stent: a national experience (with videos). Gastrointest Endosc 2015; 81: $127-135$

[10] Vazquez-Sequeiros E, Baron TH, Perez-Miranda M et al. Evaluation of the short- and long-term effectiveness and safety of fully covered self-expandable metal stents for drainage of pancreatic fluid collections: results of a Spanish nationwide registry. Gastrointest Endosc 2016; 84: 450 - 457.e452

[11] Sharaiha RZ, Tyberg A, Khashab MA et al. Endoscopic Therapy With Lumen-apposing Metal Stents Is Safe and Effective for Patients With Pancreatic Walled-off Necrosis. Clin Gastroenterol Hepatol 2016; 14 : $1797-1803$

[12] Siddiqui AA, Adler DG, Nieto J et al. EUS-guided drainage of peripancreatic fluid collections and necrosis by using a novel lumen-apposing stent: a large retrospective, multicenter U.S. experience (with videos). Gastrointest Endosc 201683: 699-707

[13] Walter D, Will U, Sanchez-Yague A et al. A novel lumen-apposing metal stent for endoscopic ultrasound-guided drainage of pancreatic fluid collections: a prospective cohort study. Endoscopy 2015; 47: $63-67$

[14] Bang JY, Hasan M, Navaneethan U et al. Lumen-apposing metal stents (LAMS) for pancreatic fluid collection (PFC) drainage: may not be business as usual. Gut 2016: doi:10.1136/gutjnl-2016-312812 [Epub ahead of print]

[15] Adler JM, Gordon SR, Sampath K et al. Su1312 Cost Effectiveness and Clinical Efficacy of Lumen Apposing Covered Self-Expanding Metal vs Plastic Stents for the Treatment of Walled off Pancreatic Necrosis. Gastrointestinal Endoscopy 2016; 83: AB347 - AB348

[16] Siddiqui AA, Kowalski TE, Loren DE et al. Fully Covered Self-Expanding Metal Stents Versus Lumen-Apposing Fully Covered Self-Expanding Metal Stent Versus Plastic Stents for Endoscopic Drainage of Pancreatic Walled-off Necrosis: Clinical Outcomes and Success. Gastrointest Endosc 2017; 85: 758 - 765

[17] Gluck M, Ross A, Irani S et al. Dual modality drainage for symptomatic walled-off pancreatic necrosis reduces length of hospitalization, radiological procedures, and number of endoscopies compared to standard percutaneous drainage. J Gastrointest Surg 2012; 16: 248 256; discussion 256-247

[18] Gluck M, Ross A, Irani S et al. Endoscopic and percutaneous drainage of symptomatic walled-off pancreatic necrosis reduces hospital stay and radiographic resources. Clin Gastroenterol Hepatol. 2010; 8: $1083-1088$

[19] Ross AS, Irani S, Gan SI et al. Dual-modality drainage of infected and symptomatic walled-off pancreatic necrosis: long-term clinical outcomes. Gastrointest Endosc 2014; 79: 929-935

[20] Fotoohi M, D’Agostino HB, Wollman B et al. Persistent pancreatocutaneous fistula after percutaneous drainage of pancreatic fluid collections: role of cause and severity of pancreatitis. Radiology 1999; 213: $573-578$

[21] Gardner TB, Coelho-Prabhu N, Gordon SR et al. Direct endoscopic necrosectomy for the treatment of walled-off pancreatic necrosis: results from a multicenter U.S. series. Gastrointest Endosc 2011; 73: $718-726$

[22] Seifert H, Biermer M, Schmitt W et al. Transluminal endoscopic necrosectomy after acute pancreatitis: a multicentre study with longterm follow-up (the GEPARD Study). Gut 2009; 58: 1260 - 1266 
[23] Banks PA, Bollen TL, Dervenis C et al. Classification of acute pancreatitis-2012: revision of the Atlanta classification and definitions by international consensus. Gut 2013; 62: 102-111

[24] Balthazar E]. Acute pancreatitis: assessment of severity with clinical and CT evaluation. Radiology 2002; 223: 603-613

[25] Irani S, Kozarek RA. The buried lumen-apposing metal stent: Is this a stent problem, location problem, or both? VideoGIE 1:25-26

[26] Cotton PB, Eisen GM, Aabakken L et al. A lexicon for endoscopic adverse events: report of an ASGE workshop. Gastrointest Endosc 2010; 71: $446-454$
[27] Bang JY, Hawes R, Bartolucci A et al. Efficacy of metal and plastic stents for transmural drainage of pancreatic fluid collections: a systematic review. Dig Endosc 2015; 27: 486 - 498

[28] Bang JY, Varadarajulu S. Endoscopic ultrasound-guided management of pancreatic pseudocysts and walled-off necrosis. Clin Endosc 2014; 47: $429-431$

[29] Larsen M, Kozarek RA. Management of Disconnected Pancreatic Duct Syndrome. Curr Treat Options Gastroenterol 2016; 14: 348 - 359

[30] Lawrence C, Howel DA, Stefan AM et al. Disconnected pancreatic tail syndrome: potential for endoscopic therapy and results of long-term follow-up. Gastrointest Endosc 2008; 67: 673-679 